\title{
ROLE OF PHYTOHORMONES IN THE CONTROL OF SYMBIOTIC NODULE DEVELOPMENT IN LEGUME PLANTS. I. CYTOKININS (review)
}

\section{E.A. DOLGIKH, A.N. KIRIENKO, I.V. LEPPYANEN, A.V. DOLGIKH}

All-Russian Research Institute for Agricultural Microbiology, Federal Agency of Scientific Organizations, 3, sh. Podbel'skogo, St. Petersburg, 196608 Russia, e-mail dol2helen@yahoo.com Acknowledgements:

Supported by the Russian Scientific Foundation (project № 14-24-00135)

Received March 18, 2016

\section{Abstract}

The influence of cytokinins on nitrogen-fixing nodule development in legume plants, as well as the molecular mechanisms of this effect and interaction with components of signaling cascade activated by nodulation inductors, the bacterial signals Nod factors, are discussed in the review. Positive role of cytokinins was first shown in the experiments with their exogenous application to plants that resulted in spontaneous nodule formation on the roots of legume plants (K.R. Libbenga, P.A.A. Harkers, 1973). The experiments with bacterial strains defective in Nod factor biosynthesis, but producing the trans-zeatin, confirmed the assumption that cytokinins are involved in the control of nodule formation (J.B. Cooper, S.R. Long, 1994). As a result the nodule-like structures are developed expressing the symbiosis-specific early nodulin genes. At the present stage of research the identification of legume mutants defective in the genes encoding receptors to cytokinins allowed to provide evidence for the involvement of cytokinins in nodulation. The inhibition of nodule development was found in Medicago truncatula mutants defective in the cytokinin receptor gene CRE1 (cytokinin response 1) and LHK1 (Lotus histidine kinase 1) in Lotus japonicus (S. Gonzalez-Rizzo et al., 2006; J.D. Murray et al., 2007). Thus inhibition of plant susceptibility to cytokinins affected both the infection thread development and nodule formation. In contrast, the strengthening of the LHK1 and CRE1 gene function in L. japonicus and M. truncatula using a recombination approach, resulted in nodule-like structure formation in the absence of rhizobia (L. Tirichine et al., 2007; E. Ovchinnikova et al., 2011). The pathways of cytokinin biosynthesis and activation have been considered, as well as their perception and signal transduction. Cytokinin accumulation may be connected with the gene expression induction, that control the biosynthesis/activation of these hormones, but the molecular mechanisms of this activation remains to be seen. Analysis showed that cytokinins are involved in signal transduction from Nod factor after the stage controlled by one of the key regulators of the signaling pathway, the calcium calmodulin-dependent kinase. This suggests that activation of the receptor to cytokinins is dependent on Nod factors. The expression of the genes encoding transcription factors NSP2, ERN1 and NIN was significantly reduced in the mutants cre 1 and $l h k l$, that allowed to conclude the activation of the receptor to cytokinins precedes the involvement of these transcription factors in signal transduction (L. Tirichine et al., 2007; J. Plet et al., 2011). The analysis has shown that cytokinins are involved in the control of early stages of organogenesis and infection development, but they are also important for nodule differentiation. In addition to local control of nodulation, cytokinins take participation in system control, i.e. in the autoregulation of nodulation. Therefore the cytokinins may play various roles in nodule development depending on their spatial and temporal activation.

Keywords: legume-rhizobial symbiosis, cytokinins, Nod factors, nodules organogenesis, rhizobial infection

The legumes-Rhizobiales symbiosis, leading to the appearance of nitrogen-fixing nodules, is the result of a finely controlled molecular and biochemical interactions between the symbionts [1]. Micro- and macrosymbiont can excrete a variety of compounds, so early search for candidate regulators of symbiosis were aimed at their identification and analysis of functional activity. Cytokininlike substances in a concentration enough to initiate organogenesis were identified among the compounds produced by rhizobia [2,3]. The ability of free rhizobia to synthetize auxins through the tryptophan-dependent and tryptophan- 
independent pathways has also determined the opportunity of these hormones to be involved in nodulation [4, 5]. Cytokinins and auxins are the hormones that play an important role in the regulation of plant growth and development, including morphogenesis in response to environmental stimuli [6-10]. In this regard, in earlier publications they were treated as the most likely candidates capable of regulating organogenesis in legums [5, 11, 12].

These ideas have been revised after other compounds secreted by rhizobia, the oligosaccharide nodulation factors (Nod factors), have been identified [13]. The adding of purified Nod factors to the plant was proved sufficient to enable a whole range of responses typical of initiation of rhizobial symbiosis. Moreover, in certain species (alfalfa Medicago sativa and soybean Glycine soja) upon the application of Nod factors there is a formation of nodules similar in structure to those induced by rhizobia [14, 15]. All the stages of the Nod factor synthesis have been further described with rhizobia genes controlling synthesis and release of these molecules [16-19]. It is found out that during the early interaction the plant excretes flavonoids to rhizosphere, which stimulate rhizobial Nod factor synthesis and production $[20,21]$. In turn, Nod factors induce a whole range of plant responses, underlying emergence of symbiotic nodules. These studies substantiated a dominant view that only Nod factors are necessary and sufficient to control nodulation.

Presently, despite the fact that the key role of Nod factors in the initiation and development of the symbiosis is not in doubt, there are experimental evidences that a change in the balance between auxin and cytokinin in plants is also necessary for nodulation.

This review discusses the classical and modern studies of the cytokinin effects on the development of nitrogen-fixing nodules in legumes, and the molecular mechanisms of its influence and interaction with the signaling cascade activated by Nod factors.

The main stages of forming symbiosis between legumes and rhizobia. The key event in the induction of nodulation at Rhizobiumlegume symbiosis is binding Nod factors to specific plant receptors, the LysMcontaining receptor-like kinases [22-26]. The subsequent launch of a signaling cascade in cells leads to activation of the infection and nodule organogenesis, which is the basis of the successful symbiosis [27].

In early response to Nod factors, the depolarization of the cell membranes in root hairs, the development of $\mathrm{Ca}^{2+}$ waves in the nucleus and perinuclear space [28-33], changes of the cytoskeleton and deformation of root hair tips [34-37], and an induction of symbiosis-specific early nodulin (ENOD) genes [38] occur. These precede curling root hairs, formation of inner bacterial microcolonis and development of infectious threads, the tubular structures through which the bacteria are delivered into the plant cell. Simultaneously, a signaling cascade is activated in the deeper layers of the root cortex leading to reactivation of the cortical cell division and the formation of a nodule primordium [1, 27, 36, 39-42]. As a nodule formation is progressing, conductive tissues [43] and functional meristem are developing to ensure nodule cell proliferation [27, 44-47].

Several components involved in a signal transduction from the receptors have been identified in legumes. These are a receptor-like kinase with the leucinerich repeats in the extracellular domain (LjSYMRK/MtDMI2); 3-hydroxy-3metilglutaril coenzyme A reductase (MtHMGR1/LjHMGR1), the primary enzyme of mevalonic acid synthesis; cationic channels (LjCASTOR, LjPOLLUX/MtDMI1), nucleoporins (LjNUP85, LjNUP133 and LjNENA), and calcium/calmodulin-dependent protein kinase (LjCCaMK/MtDMI3) [48-50]. The latter is important for decoding signals. Violation of its function leads to block- 
ing infection and nodule organogenesis.

The Nod factor signaling is required to activate transcription of most genes involved in the nodule organogenesis and the development of infection, which is controlled by transcription factors LjCYCLOPS/MtIPD3, LjNSP1/MtNSP1, LjNSP2/MtNSP2, LjNIN/MtNIN, MtERN1，LjNF-YA1/MtNF-YA1(HAP2), LjNF-YB1/MtNF-YB1, LjEFD/MtEFD [40, 51-54].

Cytokinins in nodulation. The positive role of cytokinins in nodule formation was first shown in experiments with the exogenous 6-benzylaminopurine (6-BAP), which resulted in the nodule emergence on the roots of leguminous plants. Exogenous 6-BAP was able to stimulate the cortical cell proliferation in alfalfa Medicago sativa, white clover Trifolium repens, pea Pisum sativum and Japanese lotus Lotus japonicus [55-60]. Low concentrations of cytokinins led to the appearance of nodule primordia, particularly, 6-BAP stimulated nodulation in pea P. sativum [59]. However, high concentrations of cytokinins had the opposite effect on nodulation and suppressed the generation of lateral root primordia. The authors concluded the inhibition of nodule organogenesis and lateral roots by high cytokinin concentrations to be due to stimulated ethylene production [59].

Inoculation of $M$. sativa plants using bacterial strains defective in Nod factor biosynthesis, but capable of trans-zeatin production testified in favor of the cytokinin involvement in nodulation control. There were the nodule-like structures on the roots of these plants in which the early nodulin genes $M t E$ NOD40 MtENOD2 were expressed [57]. That is, cytokinins induced responses very similar to those developed when the inoculation with a bacterial symbiont occurred [38].

Exogenous 6-BAP also stimulated early nodulin $M s E N O D 40$ and MSENOD2 gene expression in alfalfa $M$. sativa [61]. These genes are induced not only in alfalfa symbiosis with rhizobia, but also in arbuscular mycorrhiza [61]. The authors suggested that cytokinins act as the triggers of early nodulin expression both in legume-Rhizobium and mycorrhizal symbiosis. A significantly higher level of trans-zeatin was found in mycorrhizal alfalfa roots as compared with those uninoculated. Since the Rhizobium-legume symbiosis is based on the mechanisms of a more ancient symbiosis with arbuscular mycorrhizal fungi, the cytokinins involvement in plant interaction with symbiotic microorganisms can be evolutionarily ancient.

Experiments to reduce the content of cytokinins in plants also showed the stimulating role of these hormones in nodulation. Transgenic L. japonicus plants expressing genes for cytokinin catabolic enzymes of Arabidopsis and Zea mays (AtCKX2 and $Z m C K X 1$ ) showed significantly decreased root nodule number [62].

A hypothesized involvement of cytokinins in nodulation control was finally confirmed when cytokinin receptors MtCRE1 and LjLHK1 controlling the development of symbiosis were identified in the model legumes Medicago truncatula and L. japonicus [63-66]. In plants with a constitutive activation of the cytokinin MtCRE1/LjLHK1 receptor due to dominant positive mutation in the receptor gene, the nodule-like structures (spontaneous nodules) occurred in the absence of rhizobia. In particular, snf 2 mutant with spontaneous nodule formation was isolated in L. japonicus. Cloning showed the presence of a dominant mutation in LHK1 gene homologous to AHK4/CRE1 gene in Arabidopsis (Arabidopsis HISTIDINE KINASE4/CYTOKININ RESPONSE1), which is localized in the extracellular CHASE domain of the cytokinin receptor [67-69]. The snf2 mutants formed nodule-like structures free of rhizobia, which were similar to nodules, formed at bacterial inoculation [64]. Similarly, spontaneous nodulation appeared in Medicago plants transformed with genetic construct for MtCRE1 
synthesis with a replacement in the CHASE domain (L267F), which determined constitutive receptor activation [69].

In contrast, a loss-of-function mutation in the cytokinin receptor genes MtCRE1/LjLHK1 significantly reduced the number of symbiotic nodules. Rare nodulation in cre 1 and $l h k 1$ mutants has been time-shifted and controlled by additional cytokinin receptors (LjLHK1A and LjLHK3 in L. japonicus) [70]. In M. truncatula mutant cre1 plants and in those with RNAi knockdown of cytokinin receptor MtCRE1 the nodulation was disrupted, so that the number of forming nodules reduced sharply $[63,71]$. The inhibition of plant susceptibility to cytokinins affects both the development of infection threads and nodule formation $[63,71]$. Even if the infection threads were initiated, they penetrated only the epidermis and the outer cortical layers. In the nodules rarely appeared in cre $1 \mathrm{mu}-$ tants, zonation was perturbed thus indicating cytokinins to be involved both in the initiation of nodule organogenesis and in the nodule differentiation control [71].

A hyperinfected 1 (hit 1) mutant with LjLHK1 gene mutation found in L. japonicus showed a reduced number of root nodules [65, 66]. An increased susceptibility to rhizobia was characteristic of this mutant, unlike Medicago cre 1 mutants, but the infection was inhibited in the epidermis and cortex, resulting in a significantly reduced nodulation [66]. The authors obtained evidence for direct binding LjLHK1 to cytokinins, while the mutant protein lost this function.

Thus, key role of cytokinins in the initiation and development of the nodules has been shown in two model plants, M. truncatula and L. japonicus. At that, the loss of plant sensitivity to cytokinins because of improper receptor function differently affected rhizobial infection in $M$. truncatula and $L$. japonicus, which may be due to different types of nodule formation in these species [66, 71]. The role of cytokinins is not limited to regulation of early organogenesis, and they also may partake in the control of nodule differentiation.

According to the alleged involvement of cytokinins in the regulation of nodule organogenesis and rhizobial infection, LjLHK1 receptor and the cytokinin response regulators are located in the dividing cells of the outer root cortex and in the root hair cells of L. japonicus $[62,70]$. These genes are expressed in substantially wider zone in emerging nodules, while in mature nodules the expression is limited to the meristem and vascular bundles [62, 70].

During symbiotic events in $M$. truncatula, the cytokinin receptors were shown to be first associated only with dividing cells in pericycle and the inner cortex, then with the developing nodule primordia, and in the mature nodule with a meristem and invasion zone [72, 73]. Meanwhile, an activation of the cytokinin response regulators was revealed in root hair cells of $M$. truncatula when inoculation and treatment with Nod factor [73], which was confirmed by the transcriptome analysis [74]. Moreover, transcriptome analysis showed an increased expression of MtCRE1 receptor in root hair cells at inoculation [75]. That is, activation of cytokinin receptors in $M$. truncatula also occurs in root hairs.

Experiments with exogenous 6-BAP $\left(10^{-8} \mathrm{~mol} / \mathrm{l}\right)$ indicated that the initiation of nodule organogenesis is mediated by local mechanisms in root cortex cells [60]. Interestingly, the cytokinin stimulates $\operatorname{LjNIN}$ gene expression necessary for nodule organogenesis only in the root cortex [60].

The bacterial infection in the root epidermis and formation of nodule primordia in the root cortex are known to be in strong concordance $[27,76,77]$, and cytokinins can be crucial for this coordination. Thus, an additional symrk14 mutation in the double mutant L. japonicus symrk14 lhkl (recall that SYMRK is a component of signaling pathway activated by Nod factors, and LjLHK1 is a cytokinin receptor) prevented the development of infectious threads and bacterial release from these threads into the root hairs [70]. When lhk1 single mutants 
were inoculated, some bacteria reached the cells of root cortex and induced sporadic nodules due to additional cytokinin receptors (LjLHK1A, LjLHK3), whereas in double mutants the nodule development was completely blocked [70]. This suggests that the symbiotic events in the epidermis and the activation of cytokinin receptors to in the root cortex are related. Nod factors secreted by rhizobia stimulate signaling cascade in epidermal cells which is indicated by activation of the LjLHK1 receptor to cytokinin followed by a signal transmission towards root cortex [70]. This signal activates the cytokinin receptor LjLHK1 and the additional receptors LjLHK1A and LjLHK3 in root cortex, which mediate cell division. It remains unclear whether cytokinin itself is a signal molecule or there is other regulator affecting synthesis/activation of cytokinins in the root cortex. Self-influenced expression of cytokinin receptors may increase significantly due to autoregulation, then enhancing plant response to these hormones during next symbiotic events [70].

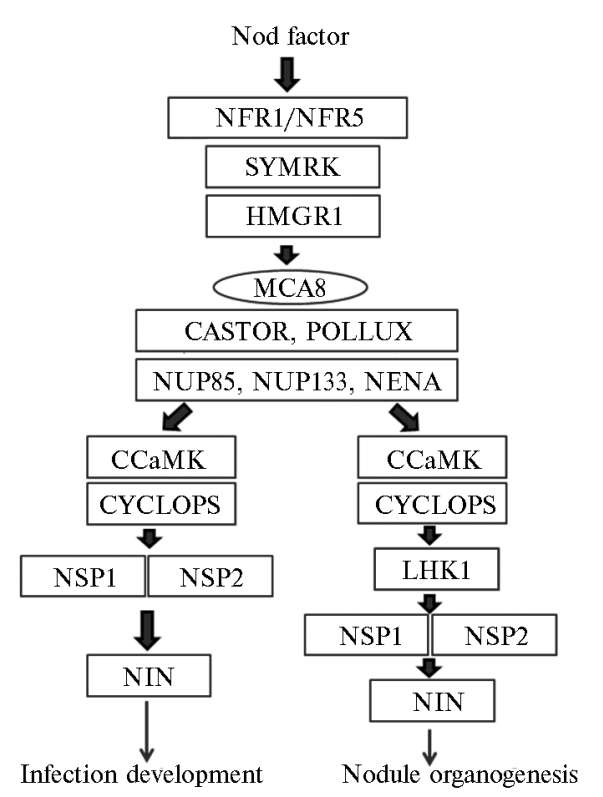

Fig. 1. Interacion of citokinins and Nod factor-dependent components of signaling pathways in Lotus japonicus (based on [76, 78]): NFR1, NFR5 - LysM-containing receptor-like kinases, SYMRK - receptor-like kinase with the leucine-rich repeats in the extracellular domain, HMGR1 - 3-hydroxy-3-metilglutaril coenzyme A reductase, MCA8 - SERCA-type calcium-ATPase, CASTOR, POLLUX - cationic channels, NUP85, NUP133, NENA - nucleoporins, CCaMK - calcium/calmodulin-dependent protein kinase (CCaMK), CYCLOPS - transcription factor, LHK1 - cytokinin receptor, NSP1, NSP2, NIN - transcription factors. cytokinin-regulated genes encoding MtRR1 and MtRR4 in M. truncatula inoculated with Sinorhizobium meliloti was significantly reduced in $\mathrm{Nod}^{-}$mutants dmi1, dmi2, dmi3 and nsp2, deficient in basic components of the Nod factor signal transmission [63]. In lotus plants it has been shown [60, 77] that activation of the LjLHK1 cytokinin receptor depends on the signal transduction associated with recognition of Nod factors. In wild-type plants, and in the mutants symRK, nup 133, nup85, castor, pollux, ccamk and cyclops the low cytokinin concentrations stimulated division of the root cortex cells and a spontaneous formation of nodules (Fig. 1) [60, 77]. Thus cytokinins were involved in nodula- 
tion after the stages, controlled by these components of the signaling pathway [60]. However, cytokinins did not cause spontaneous nodulation in nsp 1, nsp 2 and nin mutants carrying mutations in genes which encode transcription factors and are activated after CCaMK. Consequently, the cytokinin receptor activation occurs at a stage which precedes involving these transcriptional regulators in a signal transmission.

Similarly, when introducing genetic construct for LjLHK1 receptor with the L266F substitution in the CHASE domain into the mutant plants symRK, nup 133, nup85, castor, pollux, ccamk, cyclops, nsp2 and nin (see Fig. 1) (note, the L266F causes a constitutive activation of cytokinin receptor) [78], a spontaneous nodulation was observed upon cytokinin application in transgenic symRK, nup 133, nup85, castor, pollux, ccamk and cyclops plants, but not in nsp 2 and nin plants, suggesting NSP2 and NIN to be activated after the cytokinin receptor.

Exogenous cytokinins could activate genes encoding NSP2, ERN1 and NIN, the key transcriptional regulators of symbiosis [71]. Moreover, the expression of transcription factors NSP2, ERN1 and NIN was significantly reduced in cre 1 and $\operatorname{lhk} 1$ mutants deficient in cytokinin receptors. Thus, the cytokinin receptor activation precedes involvement of these transcription factors in signaling pathway $[64,71]$. Finally, the sequence binding transcriptional regulator MtRR1 (RR-B type) and found in all other cytokinin-regulated genes has been revealed in NSP2 promoter. This confirms the possibility of NSP2 gene regulation by the activation of a cytokinin receptor [79].

Cytokinin metabolism in legumes. Until now, it was unclear whether production of cytokinin-like compounds by rhizobia or synthesis/activation of plant cytokinins underlies the increase in the cytokinin content during symbiosis. The main cytokinins in higher plants are trans-zeatin (tZ), N6- $(\Delta 2-$ isopentenyl) adenine (iP), cis-zeatin (cZ), dihydrozeatin (DZ) and N6benzyladenine (BA) [80]. Bacteria, including rhizobia, carrying genes for cytokinin biosynthesis homologous to those in plants are also capable of cytokinin synthesis [81]. a series of genes involved in the metabolism cytokinins has been identified in plants (Fig. 2). Cytokinin biosynthetic precursors are free ATP and ADP, and tRNA. Synthesis of isopentenyl nucleotides from ATP or ADP, and dimethylallyl pyrophosphate (DMAPP) catalized by isopentenyltransferase (IPT), is the first step of cytokinin biosynthesis (see Fig. 2.). Additionally to IPT, tRNA-IPT with tRNA as substrate for the cis-zeatin synthesis is also found in plants [82]. At this stage, the amount of cytokinins in plant tissues is under control, and the cytokinin levels are most dramatically affected by IPT expression. Isopentenyl nucleotides can further be converted into zeatin nucleotides by the cytochrome P450 monooxygenases CYP735A [83]. Cytokinin nucleotides possess low physiological activity, so their activation by cleavage of ribose and a phosphate group is an important step in the cytokinin biosynthesis. This last step of cytokinin activation is catalyzed by $5^{\prime}$-monophosphate phosphoribohydrolase encoded by the genes of the LONELYGUY family ( $L O G)$. LOG enzymes possess phosphoribohydrolase activity and turn cytokinin nucleotides iPRMP and tZRMP into free active izopenteniladenin and zeatin [84].

Recently it is shown that the expression of genes involved in the control of cytokinin biosynthesis increases in response to rhizobial inoculation or exogenous Nod factors. In $M$. truncatula in 1 hour upon application of exogenous Nod factors the expression of MtIPT4 gene encoding isopentenyltransferase increased significantly [85]. Higher MtIPT4 expression correlated with the accumulation of cytokinins, the trans-zeatin and isopentenyl adenine, in the roots [85]. This experiment showed the activation of cytokinin biosynthesis in plants themselves as no inoculation with rhizobia was used. The expression of other 
genes (MtIPT1 and MtIPT3 in M. truncatula, and their homologs PSIPT4 and PSIPT3 in P. sativum) significantly increased on day 7 after inoculation (at initial steps of nodulation) and then elevated with the development of nodules [86]. Additionally, expression of genes LONELYGUYS (LOGS) for the enzymes activating cytokinins greatly increased with the inoculation of Medicago and pea $P$. sativum [85-87].

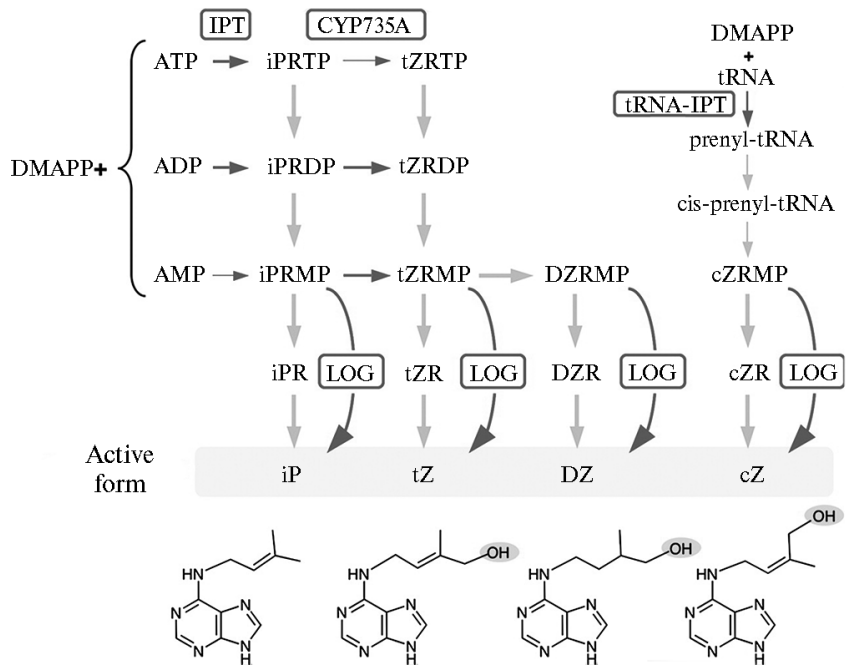

Fig. 2. Main stages in cytokinin biosynthesis [88]: DMAPP dimethylallyl pyrophosphate, iP - isopentenyl adenine, tZ trans-zeatin, DZ - dihydrozeatin, cZ - cys-zeatin, iPRMP isopentenyladenosine monophosphate, tZRMP - trans-zeatin riboside monophosphate, DZRMP - dihydrozeatin riboside monophosphate, cZRMP - cys-zeatin riboside monophosphate, iPR isopentenyladenine riboside, tZR - trans-zeatin riboside, DZR dihydrozeatin riboside, cZR - cys-zeatin riboside, IPT - isopentenyltransferase, LOG $-5^{\prime}$-monophosphate phosphoribohydrolase.

rhizobia which produce Nod factors. Rhizobia can synthesize cytokinins, but when studying cytokinin production in four different rhizobial strains capable and not capable of forming nodules, no correlation was found between the number and types of cytokinins synthesized and the ability to induce the nodule development [90].

Thus, the increase in the cytokinin level at nodulation is probably due to the activated synthesis of these hormones in the plant under the influence of Nod factors, the signaling molecules produced by rhizobia.

The participation of cytokines in the control of symbiosis autoregulation. Cytokinins are not only required to initiate nodule organogenesis (local control), but also involved in the autoregulation of nodulation (system control) [91].

It has been shown that activation of the cytokinin receptor MtCRE1/LjLHK1 is necessary to induce MtCLE13 regulatory peptides in roots of Medicago, and also CLE-RS1 and CLE-RS2 peptides in Lotus [92, 93].

Transcription factor NIN, which activation depends on MtCRE1/LjLHK1 receptor directly participates in the induction of MtCLE13, CLE-RS1 and CLE-RS2 genes. The synthesized peptides are transferred to shoots, and there they are bound to receptors MtSUNN/LjHAR1/PsSYM29, LjCLV2/PsSYM28 and LjKLAVIER, homologues to CLAVATA1, CLAVATA2 and RPK2 (TOAD2) in Arabidopsis. Upon activation of these receptors, a signal of an unknown nature is generated, which then is transmitted to the roots and blocks emergence of new 
nodules. Cytokinins can be that signal. L. japonicus was shown to respond to inoculation by an increased expression of LjIPT3 gene of shoot phloem [91]. In this, LjIPT3 activation was mediated by the components of the system of symbiosis autoregulation (receptors and regulating CLAVATA CLE-peptides), and an increase in cytokinin concentrations negatively affects nodulation [91].

Consequently, the cytokinins can play a dual role in nodualtion depending on timing and spatial factors of activation.

Thus, the coordinated regulation of nodule development mechanisms in plant-rhizobia symbiosis, which enables signaling molecules of the bacteria (Nod factors) to activate phytohormones, the plant endogenous regulators, particularly cytokinins and auxins, is of considerable interest. The data reviewed in this article allow us to propose a model in which a Nod factor-dependent activation of signaling pathway components, especially calcium/calmodulines-dependent kinase (CCaMK), leads to a local accumulation of cytokinins, which, in turn, affect the cell division in the root cortex and formation of nodule primordia. The fact that the MtCRE1/LjLHK1 cytokinin receptor mutants can form spontaneous nodules leads to the conclusion that there is a program of nodule development in the host plant, but it is activated by signaling molecules generated by rhizobia. The accumulation of cytokinins may be due to the induction of the genes that control the biosynthesis/activation of these hormones, but the molecular mechanisms of this activation remain to be seen.

\section{REFEREN C ES}

1. Schultze M., Kondorosi A. Regulation of symbiotic root nodule development. Annu. Rev. Genet., 1998, 32: 33-57 (doi: 10.1146/annurev.genet.32.1.33).

2. P hilli ps D.A., T o r r y J.G. Studies on cytokinin production by Rhizobium. Plant Physiol., 1972, 49: 11-15 (doi: 10.1104/pp.49.1.11).

3. Sturtevant D.B., Ta 11 e r B.J. Cytokinin production by Bradyrhizobium japonicum. Plant Physiol., 1989, 89: 1247-1252 (doi: 10.1111/j.1399-3054.1970.tb08880.x).

4. Thi mann K.V. On the physiology of the formation of nodules on legume roots. PNAS USA, 1936, 22: 511-514 (doi: 10.1073/pnas.22.8.511).

5. Morris R.O. Genes specifying auxin and cytokinin biosynthesis in prokaryotes. In: Plant hormones . P.J. Davies (ed.). KAP, Dordrecht, 1995, E20: 318-339 (doi: 10.1007/978-94-011-0473-9 15).

6. S a chs T., Thimann K. The role of auxins and cytokinins in the release of buds from dominance. Am. J. Bot., 1967, 54(1): 136-144 (doi: 10.2307/2440896).

7. Tanaka M., Takei K., Koji ma M., Sakakibara H., Mori H. Auxin controls local cytokinin biosynthesis in the nodal stem in apical dominance. The Plant Journal, 2006, 45(6): 1028-1036 (doi: 10.1111/j.1365-313X.2006.02656.x).

8. We rne r T., Motyka V., S t r nad M., S c h mülling T. Regulation of plant growth by cytokinin. PNAS USA, 2008, 98(18): 10487-10492 (doi: 10.1073/pnas.171304098).

9. We rner T., Köllmer I., B artrina I., Holst K., S chmülling T. New insights into the biology of cytokinin degradation. Plant Biology, 2006, 8(3): 371-381 (doi: 10.1055/s2006-923928).

10. S a k a k i b a r a H. Cytokinins: activity, biosynthesis, and translocation. Annu. Rev. Plant Biol., 2006, 57: 431-449 (doi: 10.1146/annurev.arplant.57.032905.105231).

11. Sy o no K., New comb W., Torrey J.G. Cytokinin production in relation to the development of pea root nodules. Can. J. Bot., 1976, 54: 2155-2162 (doi: 10.1139/b76-232).

12. N e w m a n J.D., D i e b old R.J., S chultz B.W., N o e l K.D. Infection of soybean and pea nodules by Rhizobium spp. purine auxotrophs in the presence of 5-aminoimidazole-4carboxamide riboside. J. Bacteriol., 1994, 176: 3286-3294 (PMCID: PMC205499).

13. S paink H., Sheeley D.M., van Brussel A.A.N., Glushka J., York W.S., Tak T., Geiger O., Kennedy E., Reinhold N., Lugtenberg B.J.J. A novel highly unsaturated fatty acid moiety of lipooligosaccharide signals determines host specificity of Rhizobium. Nature, 1991, 354: 125-130 (doi: 10.1038/354125a0).

14. Truchet G., Roche P., Lerouge P., Vasse J., Camut S., Debilly F., Prome J.C., De narie J. Sulphatedlipo-oligosaccharide signals of Rhizobium meliloti elicit root nodule organogenesis in alfalfa. Nature, 1991, 351: 670-673 (doi: 10.1038/351670a0).

15. S tokk e rmans T.J.W., P e te rs N.K. Bradyrhizobium elkanii lipo-oligosaccharide signals induce complete nodule structures on Glycine soja Siebold et. Zucc. Planta, 1994, 193: 413-420 (doi: 10.1007/BF00201821). 
16. Cárdenas L., Domínguez J., Quinto C., Lypez-La ra I.M., Lugtenberg B.J., S paink H.P., Rad e make r G.J., Have rk a m p J., Tho m a s-O a t e s J.E. Isolation, chemical structures and biological activity of the lipo-chitin oligosaccharide nodulation signals from Rhizobium etli. Plant Mol. Biol., 1995, 29(3): 453-464 (doi: 10.1007/BF00020977).

17. Ritse ma T., Lugte nberg B.J., S paink H.P. Acyl-acyl carrier protein is a donor of fatty acids in the NodA-dependent step in biosynthesis of lipochitin oligosaccharides by rhizobia. J. Bacteriol., 1997, 179(12): 4053-4055 (PMCID: PMC179219).

18. Corvera A., Promé D., Promé J.-C., Martínez-Romero E., Ro mero D. The nolL gene from Rhizobium etli determines nodulation efficiency by mediating the acetylation of the fucosyl residue in the Nodulation factor. Mol. Plant-Microbe Interact., 1999, 12(3): 236-246 (doi: 10.1094/MPMI.1999.12.3.236).

19. Perret X., S t a e helin C., B roughto n W.J. Molecular basis of symbiotic promiscuity. Microbiol. Mol. Biol. Res., 2000, 64(1): 180-201 (doi: 10.1128/MMBR.64.1.180-201.2000).

20. De narie J., D ebelle F., Prome J.C. Rhizobium lipo-chitooligosaccharide nodulation factors: signaling molecules mediating recognition and morphogenesis. Annu. Rev. Biochem., 1996, 65: 503-535 (doi: 10.1146/annurev.bi.65.070196.002443).

21. L o ng S.R. Rhizobium symbiosis: Nod factors in perspective. Plant Cell, 1996, 8: 1885-1898 (doi: $10.1105 / \mathrm{tpc} .8 .10 .1885$ ).

22. Madsen E.B., Madsen L.H., Radutoiu S., Olbryt M., Rakwalska M., S z c yglowski K., S a to S., Kaneko T., Tabata S., S andal N., Stouga ard J. A receptor kinase gene of the LysM type is involved in legume perception of rhizobial signals. Nature, 2003, 425: 637-640 (doi: 10.1038/nature02045).

23. Radutoiu S., Madsen L.H., Madsen E.B., Felle H.H., Umehara Y., Gronlund M., S a to S., Naka mura Y., Tabat a S., S a ndal N., Stouga ard J. Plant recognition of symbiotic bacteria requires two LysM receptor-like kinases. Nature, 2003, 425: 569-570 (doi: 10.1038/nature02039).

24. Ben Amor B., Shaw S.L., Oldroyd G.E.D., Maillet F., Penmetsa R., Cook D., Lo ng S.R., D e narie J., Gough C. The NFP locus of Medicago truncatula controls an early step of Nod factor signal transduction upstream of a rapid calcium flux and root hair deformation. Plant J., 2003, 34: 1-12 (doi: 10.1046/j.1365-313X.2003.01743.x).

25. Arrighi J.-F., Barre A., ben Amor B., Bersoult A., Soriano L.C., Mirabells R., de Carvalho-Niebel F., Journet E.-P., Gherardi M., Huguet T., Geurts R., Denarie J., Rouge P., Gough C. The Medicago trancatula lysine motifreceptor-like kinase gene family includes NFP and new nodule-expressed genes. Plant Physiol., 2006, 142: 265-279 (doi: 10.1104/pp.106.084657).

26. Smit P., Limpens E., Geurts R., Fedorova E., Dolgikh E., Gough C., B isseling T. Medicago LYK3 an entry receptor in rhizobial Nod factor signaling. Plant Physiol., 2007, 145(1): 183-191 (doi: 10.1104/pp.107.100495).

27. Oldroyd G.E.D., Downi e J.A. Coordinating nodule morphogenesis with Rhizobial infection in legumes. Annu. Rev. Plant Biol., 2008, 59: 519-546 (doi: 10.1146/annurev.arplant.59.032607.092839).

28. Ehrhardt D.W., A tkinson E.M., Long S.R. Depolarization of alfalfa root hair membrane potential by Rhizobium meliloti Nod factors. Science, 1992, 256(5059): 998-1000 (doi: 10.1126/science.10744524).

29. E h rhardt D.W., Wa is R., L o ng S.R. Calcium spiking in plant root hairs responding to Rhizobium nodulation signals. Cell, 1996, 85(5): 673-681 (doi: 10.1016/S0092-8674(00)81234-9).

30. Ha r r is J.M., W a is R., Lo ng S.R. Rhizobium-induced calcium spiking in Lotus japonicus. Mol. Plant-Microbe Interact., 2003, 16: 335-341 (doi: 10.1094/MPMI.2003.16.4.335).

31. Felle H.H., Kondorosi E., Kondorosi A., Schultze M. Nod factors modulate the concentration of cytosolic free calcium differently in growing and non-growing root hairs of Medicago sativa L. Planta, 1999, 209: 207-212 (doi: 10.1007/s004250050624).

32. Engstrom E.M., Ehrhardt D.W., Mitra R.M., Long S.R. Pharmacological analysis of Nod factor-induced calcium spiking in Medicago truncatula: evidence for the requirement of type IIA calcium pumps and phosphoinositide signaling. Plant Physiol., 2002, 128: 1390-1401 (doi: 10.1104/pp.010691).

33. Charron D., Pingret J.L., Chabaud M., J ournet E.P., B a rker D.G. Pharmacological evidence that multiple phospholipid signaling pathways link Rhizobium nodulation factor perception in Medicago truncatula root hairs to intracellular responses, including $\mathrm{Ca}^{2+}$ spiking and specific ENOD gene expression. Plant Physiol., 2004, 136: 3582-3593 (doi: 10.1104/pp.104.051110).

34. Van B russe 1 A.A.N., Bakhuizen R., Van Spronsen P.C., Spaink H.P., Tak T., Lugte nbe rg B.J.J., Kijn e J.W. Induction of preinfection thread structures in the leguminous host plant by mitogeniclipooligosaccharides of Rhizobium. Science, 1992, 257: 70-72 (doi: 10.1126/science.257.5066.70).

35. de Ruijter N.C.A., B is seling T., Emons A.M.C. Rhizobium Nod factors induce an increase in sub-apical fine bundles of actin filaments in Vicia sativa root hairs within minutes. Mol. Plant Microbe Interact., 1999, 12: 829-832 (doi: 10.1094/MPMI.1999.12.9.829).

36. Timmers A.C.J., Auriac M.-C., Truche G. Refined analysis of early symbiotic steps 
of the Rhizobium-Medicago interaction in relationship with microtubular cytoskeleton rearrangements. Development, 1999, 126: 3617-3628 (PMID: 10409507).

37. Lerouge P., Roche P., Faucher C., Maillet F., Truchet G., Prome J.C., $\mathrm{D}$ e $\mathrm{n}$ a ri e J. Symbiotic host-specificity of Rhizobium meliloti is determined by a sulphated and acylated glucosamine oligosaccharide signal. Nature, 1990, 19: 781-784 (doi: 10.1038/344781a0).

38. Horvath B., Heidstra R., Lados M., Moerman M., S paink H.P., Prome J.-C., $\mathrm{V}$ a n K a m m e $\mathrm{n}$ A., B is s e 1 ing T. Lipo-oligosaccharides of Rhizobium induce infection related early nodulin gene expression in pea root hairs. Plant J., 1993, 4: 727-733 (doi: 10.1046/j.1365-313X.1993.04040727.x).

39. B au er P., Ratet P., Crespi M., Schultze M., Kondorosi A. Nod factors and cytokinins induce similar cortical cell division, amyloplast deposition and MsEnod12A expression patterns in alfalfa roots. Plant J., 1996, 10: 91-105 (doi: 10.1046/j.1365-313X.1996.10010091.x).

40. D o w n i e J.A., W a $1 \mathrm{k}$ e r S.A. Plant responses to nodulation factors. Curr. Opin. Plant Biol., 1999, 2: 483-489 (doi: 10.1016/S1369-5266(99)00018-7).

41. Marsh J.F., Rakocevic A., Mitra R.M., Brocard L., Sun J., Eschstruth A., Long S.R., Schultze M., Pascal Ratet P., Oldroyd G.E.D. Medicago truncatula NIN is essential for rhizobial-independent nodule organogenesis induced by autoactive calcium/calmodulin-dependent protein kinase. Plant Physiol., 2007, 144: 324-335 (doi: 10.1104/pp.106.093021).

42. S c h a u s e r L., Wi e lo c h W., S t o u ga a rd J. A plant regulator controlling development of symbiotic root nodules. Nature, 1999, 402: 191-195 (doi: 10.1038/46058).

43. de Billy F., Grosjean C., May S., Bennett M., Cullimore J. Expression studies on AUX1-like genes in Medicago truncatula suggest that auxin is required at two steps in early nodule development. Mol. Plant-Microbe Interact., 2001, 14(3): 267-277 (doi: 10.1094/MPMI.2001.14.3.267).

44. Pate J.S., Gunning B.E.S., Briarty L.G. Ultrastructure and functioning of the transport system of the leguminous root nodule. Planta, 1969, 85: 11-34 (doi: 10.1007/BF00387658).

45. Hirsch A.M., B huvaneswari J.G., Torrey J.G., B isseling T. Early nodulin genes are induced in alfalfa root outgrowths elicited by auxin transport inhibitors. PNAS USA, 1989, 86: 1244-1248 (doi: 10.1073/pnas.86.4.1244).

46. Sprent J.I., Embrapa J.I. Root nodule anatomy, type of export product and evolutionary origin in some Leguminosae. Plant Cell Environ., 1979, 3: 35-43 (doi: 10.1111/13653040.ep11580516).

47. Crespi M., Frugie r F. De novo organ formation from a differentiated cells: root nodule organogenesis. Sci. Signal., 2008, 1(49): re11 (doi: 10.1126/scisignal.149re11).

48. Endre G., Kereszt A., Kevei Z., Mihacea S., Kalo P., Kiss G.B. A receptor kinase gene regulating symbiotic nodule development. Nature, 2002, 417: 962-966 (doi: 10.1038/nature00842).

49. Ane J.-M., Kiss G.B., Riely B.K., Penmetsa R., Oldroyd G.E.D., Ayax C., Levy J., Debelle F., Baek J.-M., Kalo P., Rosenberg C., Roe B.A., Long S.R., D e n a ri e J., C o ok D.R.. Medicago trancatula DMI1 required for bacterial and fungal symbioses in legumes. Science, 2004, 303: 1364-1367 (doi: 10.1126/science.1092986).

50. Old royd G.E., D o w n i e J.A. Nuclear calcium changes at the core of symbiosis signalling. Curr. Opin. Plant Biol., 2006, 9: 351-357 (doi: 10.1016/j.pbi.2006.05.003).

51. S mit P., Ra edts J., Portyanko V., D ebelle F., Gough C., Bisseling T., G e u rts R. NSP1 of the GRAS protein family is essential for rhizobial Nod factor-induced transcription. Science, 2005, 308: 1789-1790 (doi: 10.1126/science.1111025).

52. Yano K., Tansengco M.L., Hio T., Higashi K., Murooka Y., I maizumiA n raku H., Kawaguchi M., H y a shi M. New nodulation mutants responsible for infection thread development in Lotus japonicus. Mol. Plant-Microbe Interact., 2006, 19(7): 801810 (doi: 10.1094/MPMI-19-0801).

53. Andriankaja A., Boisson-Dernie A., Frances L., Sauviac L., Jaunea u A., B arker D.G., d e Carvalho-Ni ebe 1 F. AP2-ERF transcription factors mediate Nod factor dependent $M t E N O D 11$ activation in root hairs via a novel cis-regulatory motif. Plant Cell, 2007, 19: 2866-2885 (doi: 10.1105/tpc.107.052944).

54. Middleton P.H., J a k ab J., Penmetsa R.V., Starker C.G., Doll J., Kaly P., Prabhu R., Marsh J.F., Mitra R.M., Kereszt A., Dudas B., Van den B o s ch K., Lo ng S.R., Cook D.R., K is s G.B., Old roy d G.E. An ERF transcription factor in Medicago truncatula that is essential for Nod factor signal transduction. Plant Cell, 2007, 19: 1221-1234 (doi: 10.1105/tpc.106.048264).

55. Libbe nga K.R., Harkes P.A.A. Initial proliferation of cortical cells in the formation of root nodules in Pisum sativum L. Planta, 1973, 114: 17-28 (doi: 10.1007/BF00390281).

56. F a ng Y., Hirs ch A.M. Studying early nodulin gene ENOD4O expression and induction by nodulation factor and cytokinin in transgenic alfalfa. Plant Physiol., 1998, 116: 53-68 (doi: $10.1104 /$ pp.116.1.53).

57. C o o p e r J.B., L o ng S.R. Morphogenetic rescue of Rhizobium meliloti nodulation mutants by trans-zeatin secretion. Plant Cell, 1994, 6: 215-225 (doi: 10.1105/tpc.6.2.215).

58. Mathesius U., Charon C., Rolfe B.G., Kondorosi A., Crespi M. Temporal 
and spatial order of events during the induction of cortical cell divisions in white clover by $R h i$ zobium leguminosarum bv trifolii inoculation or localized cytokinin addition. Mol. Plant-Microbe Interact., 2000, 13: 617-628 (doi: 10.1094/MPMI.2000.13.6.617).

59. L o r t e a u M.-A., F e rgu s o n B.J., Gu in e l F.C. Effects of cytokinin on ethylene production and nodulation in pea (Pisum sativum) cv. Sparkle. Physiologia Plantarum, 2001, 112: 421428 (doi: 10.1034/j.1399-3054.2001.1120316.x).

60. Heckmann A.B., S andal N., Bek A.S., Madsen L.H., Jurkiewicz A., Nie 1s e n M.W., Tirichine L., S to uga ard J. Cytokinin induction of root nodule primordia in Lotus japonicus is regulated by a mechanism operating in the root cortex. Mol. Plant-Microbe Interact., 2011, 24(11): 1385-1395 (doi: 10.1094/MPMI-05-11-0142).

61. van Rhijn P., Fang Y., Galili S., Shaul O., Atzmon N., Wininger S., Eshed Y., Lum M., Li Y., To V., Fujishig N., Kapulnik Y., Hirsch A.M. Expression of early nodulin genes in alfalfa mycorrhizae indicates that signal transduction pathways used in forming arbuscular mycorrhizae and Rhizobium-induced nodules may be conserved. PNAS USA, 1997, 94: 5467-5472 (doi: 10.1073/pnas.94.10.5467).

62. Lohar D.P., S chaff J.E., Laske y J.G., K i e b e r J.J., B ilyeu K.D., B i rd D.M. Cytokinins play opposite roles in lateral root formation, and nematode and Rhizobial symbioses. Plant J., 2004, 38: 203-214 (doi: 10.1111/j.1365-313X.2004.02038.x).

63. Gonzalez-Rizzo S., Crespi M., Frugier F. The Medicago truncatula CRE1 cytokinin receptor regulates lateral root development and early symbiotic interaction with Sinorhizobium meliloti. Plant Cell, 2006, 18: 2680-2693 (doi: 10.1105/tpc.106.043778).

64. Tirichine L., Sandal N., Madsen L.H., Radutoiu S., Albrektsen A.S., Sato S., Asamizu E., Tabat a S., Stouga a rd J. A gain-of-function mutation in a cytokinin receptor triggers spontaneous root nodule organogenesis. Science, 2007, 315: 104-107 (doi: 10.1126/science.1132397).

65. Murray J., Karas B., Ross L., Brachmann A., Wagg C., Geil R., Perry J., Nowakowski K., M a Gillivary M., Held M., Stougaard J., Peterson L., Parniske M., Szczyglowski K. Genetic suppressors of the Lotus japonicus har1-1 hypernodulation phenotype. Mol. Plant-Microbe Interact., 2006, 19(10): 1082-1091 (doi: 10.1094/MPMI-19-1082).

66. Murray J.D., Karas B.J., S ato S., Tabata S., A myot L., Szczyglowski K. A cytokinin perception mutant colonized by Rhizobium in the absence of nodule organogenesis. Science, 2007, 315: 101-104 (doi: 10.1126/science.1132514).

67. Inoue T., Higuchi M., Hashimoto Y., Seki M., Kobay ashi M., Kato T., $\mathrm{T}$ a b a t a S., S h i n o z a k i K., K a k i m o t o T. Identification of CRE1 as a cytokinin receptor from Arabidopsis. Nature, 2001, 409: 1060-1063 (doi: 10.1038/35059117).

68. Suzuki T., Miwa K., Ishikawa K., Ya mad a H., Aiba H., Mizuno T. The Arabidopsis sensor His-kinase, AHK4, can respond to cytokinins. Plant Cell Physiol., 2001, 42: 107-113 (doi: 10.1093/pcp/pce037).

69. Ovchinnikova E., Journet E.-P., Chabaud M., Cosson V., Ratet P., Duc G., Fedorova E., Wei Liu W., Rik Op den Camp R., Zhukov V., Tikhonovi ch I., B o ris ov A., B is s e ling T., Li mpens E. IPD3 controls the formation of nitrogen-fixing symbiosomes in pea and Medicago spp. Mol. Plant-Microbe Interact., 2011, 24(11): 1333-1344 (doi: 10.1094/MPMI-01-11-0013).

70. Held M., Hou H., Miri M., Huynh C., Ross L., Hossain M.S., Sato S., Tabata S., Perry J., Wang T.L., Szczyglowski K. Lotus japonicus cytokinin receptors work partially redundantly to mediate nodule formation. Plant Cell, 2014, 26: 678-694 (doi: 10.1105/tpc.113.119362).

71. Plet J., Wasson A., Ariel F., Le Signor C., Baker D., Mathesius U., Crespi M., Frugier F. MtCRE1-dependent cytokinin signaling integrates bacterial and plant cues to coordinate symbiotic nodule organogenesis in Medicago truncatula. Plant J., 2011, 65: 622-633 (doi: 10.1111/j.1365-313X.2010.04447.x).

72. Lohar D.P., Sharopova N., Endre G., Pecuela S., Samac D., Town C., $\mathrm{S}$ ilve rste in K.A., Vande $\mathrm{nB}$ os ch K.A. Transcript analysis of early nodulation events in Medicago truncatula. Plant Physiol., 2006, 140: 221-234 (doi: 10.1104/pp.105.070326).

73. Op den Camp R.H., De Mita S., Lillo A., C a o Q., Limpens E., Biss eling T., G e urts R. A phylogenetic strategy based on a legume-specific whole genome duplication yields symbiotic cytokinin type-A response regulators. Plant Physiol., 2011, 157: 2013-2022 (doi: 10.1104/pp.111.187526).

74. Larrainzar E., Riely B.K., Kim S.C., Carrasquilla-Garcia N., Yu H-Y., Hwang H.-J., Oh M., Kim G.B., Surendrarao A.K., Chasman D., Si ahpirani A.F., Penmetsa R., Le e G.-S., Kim N., Roy S., Jeong-Hwan Mun L.-H., C o ok D.R. Deep sequencing of the Medicago truncatula root transcriptome reveals a massive and early interaction between nodulation factor and ethylene signals. Plant Physiol., 2015, 169: 233-265 (doi: 10.1104/pp.15.00350).

75. Breakspear A., Liu C., Roy S., Stacey N., Rogers C., Trick M., Morieri G., Mys o re K.S., We n J., Old royd G.E.D., Downi e J.A., Murray J.D. The root hair «infectome» of Medicago truncatula uncovers changes in cell cycle genes and reveals a re- 
quirement for Auxin signaling in rhizobial infection. Plant Cell, 2014, 26: 4680-4701 (doi: 10.1105/tpc.114.133496).

76. Genre A., Russo G. Does a common pathway transduce symbiotic signals in plantmicrobe interactions? Front. Plant Sci., 2016, 7: A96 (doi: 10.3389/fpls.2016.00096).

77. Madsen L.H., Tirichine L., Jurkiewicz A., Sullivan J.T., Heckmann A.B., $\mathrm{B}$ e k A.S. The molecular network governing nodule organogenesis and infection in the model legume Lotus japonicus. Nat. Commun., 2010, 1: 1-10 (doi: 10.1038/ncomms1009).

78. Hay a shi T., B anba M., Shimoda Y., Kouchi H., Hay as hi M., I maizumiA n r a k $\mathrm{H}$. A dominant function of CCaMK in intracellular accommodation of bacterial and fungal endosymbionts. Plant J., 2010, 63: 141-154 (doi: 10.1111/j.1365-313X.2010.04228.x).

79. Ariel F., Brault-Hernandez M., Laffont C., Huault E., Brault M., Plet J., Mo ison M., Blanchet S., Ichanté J.L., Chabaud M., Carrere S., Crespi M., $\mathrm{C}$ h a n R.L., Fru gi e r F. Two direct targets of cytokinin signaling regulate symbiotic nodulation in Medicago truncatula. Plant Cell, 2012, 24: 3838-3852 (doi: 10.1105/tpc.112.103267).

80. Mok D.W., M o k M.C. Cytokinin metabolism and action. Annu. Rev. Plant Physiol. Plant Mol. Biol., 2001, 52: 89-118 (doi: 10.1146/annurev.arplant.52.1.89).

81. Costacurta A., Vanderleyden J. Synthesis of phytohormones by plant associated bacteria. Crit. Rev. Microbiol., 1995, 21: 1-18 (doi: 10.3109/10408419509113531).

82. Miyawaki K., Tarkowski P., Matsumoto-Kitano M., Kato T., Sato S., Tarkowska D., Tabat a S., S a ndberg G., Kaki moto T. Roles of Arabidopsis ATP/ADP isopentenyltransferases and tRNA isopentenyltransferases in cytokinin biosynthesis. PNAS USA, 2006, 103(44): 16598-16603 (doi: 10.1073/pnas.0603522103).

83. T a k e i K., Y a m a y a T., S a k a k i b a r a H. Arabidopsis CYP735A1 and CYP735A2 encode cytokinin hydroxylases that catalyze the biosynthesis of trans-zeatin. J. Biol. Chem., 2004, 279(40): 41866-41872 (doi: 10.1074/jbc. M406337200).

84. Kurakawa T., Ueda N., Maekawa M., Kobayashi K., Koji ma M., Nagato Y., $\mathrm{S}$ ak akibara H., Ky z u k a J. Direct control of shoot meristem activity by a cytokininactivating enzyme. Nature, 2007, 445(7128): 652-655 (doi: 10.1038/nature05504).

85. van Zeijll A., Op den Camp R.H.M., Deinum E.E., Charnikhova T., Franssen H., Op den Camp H.J.M., Bouwmeester H., Kohlen W., Bisseling T., G e u rts R. Rhizobium lipo-chitooligosaccharide signaling triggers accumulation of cytokinins in Medicago truncatula roots. Mol. Plant, 2015, 8(8): 1213-1226 (doi: 10.1016/j.molp.2015.03.010).

86. Azarakhsh M., Kirienko A.N., Zhukov V., Lebedeva M.A., Dolgikh E.A., Lu tov a L.A. KNOTTED1-LIKE HOMEOBOX 3: a new regulator of symbiotic nodule development. J. Exp. Bot., 2015, 66(22): 7181-7195 (doi: 10.1093/jxb/erv414).

87. Mortie r V., Was o n A., J aw orek P., De Keyser A., D e croos M., Holsters M., Tarkowski P., Mathesius U., Goormachtig S. Role of LONELY $G U Y$ genes in indeterminate nodulation on Medicago truncatula. New Phytologist, 2014, 202(2): 582-593 (doi: 10.1111/nph.12681).

88. Hirose N., Takei K. Regulation of cytokinin biosynthesis, compartmentalization and translocation. J. Exp. Bot., 2008, 59(1): 75-83 (doi: 10.1093/jxb/erm157).

89. Chen Y., Chen W., Li X., Jiang H., Wu P., Xia K., Y ang Y., Wu G. Knockdown of LjIPT3 influences nodule development in Lotus japonicus. Plant Cell Physiol., 2014, 55(1): 183-193 (doi: 10.1093/pcp/pct171).

90. Kisiala A., Laffont C., Emery J.R.N., Frugier F. Bioactive cytokinins are selectively secreted by Sinorhizobium meliloti nodulating and nonnodulating strains. Mol. PlantMicrobe Interact., 2013, 26: 1225-1231 (doi: 10.1094/MPMI-02-13-0054-R).

91. S a saki T., Suzaki T., S oy a no T., Ko j i ma M., S a kakibara H., Kawagu c h i M. Shoot-derived cytokinins systemically regulate root nodulation. Nature, 2014, 5: 4983 (doi: 10.1038/ncomms5983).

92. Mortier V., DeWever E., Vuylsteke M., Holsters M., Goormachtig S. Nodule numbers are governed by interaction between CLE peptides and cytokinin signaling. Plant J., 2012, 70: 367-376 (doi: 10.1111/j.1365-313X.2011.04881.x).

93. S oy a no T., Hi rak aw a H., S a to S., H a y sh i M., Kawagu c hi M. Nodule inception creates a long-distance negative feedback loop involved in homeostatic regulation of nodule organ production. PNAS USA, 2014, 111: 14607-14612 (doi: 10.1073/pnas.1412716111). 